\title{
A Educação pela Pesquisa como abordagem facilitadora da argumentação dialógica
}

\author{
Education through Research as a facilitating approach to \\ dialogical argumentation
}

\author{
Thelma Duarte Brandolt Borges (thelmadbb@hotmail.com) \\ Valderez Marina do Rosário Lima (valderez.lima@pucrs.br) \\ Pontifícia Universidade Católica do Rio Grande do Sul - PUCRS
}

\begin{abstract}
Resumo: O presente artigo constitui um recorte de uma pesquisa realizada em nível de doutorado e que tem a argumentação em sala de aula como escopo central. A partir de entendimentos decorrentes de uma aproximação com o tema e do reconhecimento de seu aspecto nebuloso e complexo, emergiu o delineamento dessa investigação. Tal delineamento partiu de um olhar voltado a abordagens que reconhecem a pesquisa como princípio pedagógico e que, portanto, valorizam os processos argumentativos para a reconstrução do conhecimento. Envolveu, ainda, a indicação de escolha por uma perspectiva de ênfase para o estudo e o desenvolvimento da argumentação por meio da apresentação de três perspectivas possíveis, quais sejam: a lógica, a retórica e a dialógica. Definidos esses marcos, estabeleceu-se como objetivo central desse estudo avaliar o processo de construção de argumentos desenvolvido por meio da Educação pela Pesquisa à luz de distintas vertentes argumentativas. Em termos metodológicos, o estudo caracterizou-se como qualitativo, de natureza teórica. Nele, foi produzida a tessitura de um arcabouço teórico que procurou evidenciar distanciamentos e pontos de contato entre as principais vertentes argumentativas e os pressupostos da Educação pela Pesquisa. Os resultados revelaram aproximações com a perspectiva dialógica, conduzindo à conclusão de que a concepção, a intencionalidade e a operacionalização da argumentação desenvolvida por meio da Educação pela Pesquisa associam-se à vertente dialógica do tema.
\end{abstract}

Palavras-chave: Argumentação Dialógica; Educação pela Pesquisa; Ensino de Ciências.

Abstract: This article constitutes a section of a research carried out at the doctoral level
and that has argumentation in the classroom as a central scope. Based on understandings
resulting from an approximation with the theme and the recognition of its cloudy and
complex aspect, the design of this investigation emerged. This design started from a
look focused on approaches that recognize research as a pedagogical principle and,
therefore, value argumentative processes for the reconstruction of knowledge. It also
involved the indication of choice from a perspective of emphasis for the study and
development of argumentation, through the presentation of three possible perspectives,
which are logic, rhetoric and dialogical. Defined these milestones, it was established as
the central objective of this study to evaluate the process of construction of arguments
developed by Education through Research in the light of different arguments. In
methodological terms, the study was characterized as qualitative, of theoretical nature.
In it, the construction of a theoretical framework was produces, which sought to show
distances and points of contact between the main arguments and the assumptions of

Recebido em: $01 / 09 / 2020$

Aceito em: $27 / 10 / 2020$ 
Education through Research. The results revealed similarities with the dialogical perspective, leading to the conclusion that the conception, intentionality and operationalization of the argument developed by Education through Research are associated with the dialogical aspect of the theme.

Keywords: Dialogical Argumentation Education through Research; Science Teaching.

\section{INTRODUÇÃO}

O estudo da argumentação compõe, ao longo do tempo, o escopo de pesquisas associadas a diferentes áreas do conhecimento. Tais pesquisas, por sua vez, lançam luzes sobre questões centrais e tangenciais que constituem a temática da argumentação a partir de distintos enfoques. Sendo assim, a historicidade, a abrangência e a complexidade características do tema se consolidam como elementos que desafiam pesquisadores interessados em contribuir com a construção de conhecimentos atinentes a esse importante processo de raciocínio.

$\mathrm{Na}$ esfera educacional, foco de interesse da presente investigação, prevalece o entendimento de que, apesar de constituir em terreno fértil para a promoção da argumentação, a escola nunca se mostrou muito à vontade com o desenvolvimento dessa competência (CHARAUDEAU, 2008). A predominância da pedagogia tradicional, baseada em formas transmissivas de ensino, é utilizada na tentativa de justificar a escassez do fomento à argumentação em sala de aula. Essa justificativa decorre de se pressupor como pré-requisito ao desenvolvimento da competência argumentativa na escola a criação de um ambiente onde o aluno seja protagonista, ou seja, tenha vez e voz na elaboração e exposição de entendimentos.

$\mathrm{Na}$ atualidade, ainda que a temática seja considerada emergente, especialmente no ensino de Ciências, a promoção da competência argumentativa baseia-se em modelos de arquitetura do argumento alicerçados na lógica (LIMA; BRANDOLT-BORGES; RAMOS, 2018). Sendo assim, percebe-se que a argumentação em sala de aula vem sendo trabalhada, de forma geral, a partir da reprodução de padrões que não exploram os benefícios comumente atribuídos à argumentação no ensino, na medida em que deixam de contemplar questões cognitivas, comunicacionais e investigativas. A discrepância entre as potencialidades e o pouco ou inadequado uso que se faz da argumentação traz à tona a premência de repensar as práticas escolares que a envolvem.

Entende-se, nesse sentido, que a perspectiva construtivista de ensino e aprendizagem surge como um dos caminhos possíveis para qualificar o 
desenvolvimento da competência argumentativa na escola, pois vai ao encontro do alcance de objetivos educacionais contemporâneos emancipatórios. Imersos nessa perspectiva, o Educar pela Pesquisa (DEMO, 2007) e a Pesquisa em Sala de Aula (MORAES; GALIAZZI; RAMOS, 2002) - nesse espaço congregados pelo termo Educação pela Pesquisa (EPP) - despontam como possibilidades para esse intento, tendo em vista tratarem-se de abordagens que preconizam a pesquisa como princípio pedagógico e evidenciam a construção de argumentos como etapa essencial ao ensino e à aprendizagem, prezando pela autonomia e pelo protagonismo estudantil.

A partir das percepções explicitadas que, entre outras questões, denunciam a centralidade da argumentação na EPP, o presente estudo pretende construir teoria acerca da intersecção entre Educação pela Pesquisa e Argumentação, com o objetivo de avaliar os processos de construção de argumentos desenvolvidos por meio da Educação pela Pesquisa à luz de distintas vertentes argumentativas. Busca-se responder, com isso, à seguinte questão: Qual(is) vertente(s) argumentativa(s) encontra(m)-se associada(s) aos processos de construção de argumentos desenvolvidos por meio da Educação pela Pesquisa? Tal pergunta procurará ser respondida por meio da tessitura de um arcabouço teórico sobre o tema, o qual entrelaçará pontos de contato e dissonâncias entre pressupostos da EPP e aspectos que caracterizam as principais vertentes argumentativas.

O texto está organizado em seções. Na introdução são apresentados o tema e sua importância, assim como o objetivo e a questão de pesquisa. A seção metodológica é explicitada a seguir, nela é definida a abordagem investigativa; o tipo de pesquisa desenvolvida; assim como a forma de coleta e análise dos dados. No aporte teórico são destacados os marcos que balizam e fundamentam esse estudo e que, tendo em vista a sua natureza teórica, já constituem e anunciam preliminarmente algumas questões a serem analisadas. Os resultados são discutidos em seção própria que interpreta os achados, enaltecendo as contribuições advindas da análise. As considerações finais são seguidas das referências bibliográficas.

\section{CAMINHOS METODOLÓGICOS}

Em termos metodológicos, este estudo caracteriza-se como qualitativo de natureza teórica. Demo (1994) vincula esse tipo de pesquisa à reconstrução de teorias, à elaboração de quadros de referência e à discussão de condições explicativas da realidade. 
A natureza da presente pesquisa vem a atender, portanto, uma importante demanda contemporânea relacionada à necessidade de análise, aprofundamento e proposição de ideias referentes ao uso da argumentação na esfera educacional. De forma mais específica, busca contribuir para o entendimento da argumentação desenvolvida em abordagens de ensino que reconhecem a pesquisa como princípio pedagógico, como o Educar pela Pesquisa e a Pesquisa em Sala de Aula, aqui reunidas pela designação Educação pela Pesquisa.

A tese de Pauletti (2018) embasa a fusão dos termos justificando, para isso, a proximidade entre seus conceitos e a semelhança entre seus pressupostos. Para ela, "a Pesquisa em Sala de Aula tem forte influência do Educar pela Pesquisa, bem como é entendida, pelos seus próprios autores, como uma aplicação prática do Educar pela Pesquisa" (ibid., p.14), ou seja, como o Educar pela Pesquisa posto em ação.

Ressalta-se, a esse respeito, que a produção de informações sobre o tema, ainda que não pressuponha uma imediata intervenção na realidade, tem papel decisivo na construção das condições requeridas para tanto, tendo em vista que representa instrumento principal de intervenção qualificada. Destaca-se, ainda, que construções teóricas como essa demandam rigor conceitual, análise acurada, desempenho lógico, capacidade explicativa e argumentativa, sendo a última considerada a arte central da pesquisa e da ciência (DEMO, 1994).

\section{TESSITURA TEÓRICA}

\section{a. Educação pela Pesquisa}

Conforme anunciado preliminarmente, o termo Educação pela Pesquisa é aqui utilizado na intenção de reunir duas abordagens que, embora distintas, por vezes são citadas como sinônimos. A similaridade e a complementaridade entre os pressupostos do Educar pela Pesquisa (DEMO, 2007) e da Pesquisa em Sala de Aula (MORAES; GALIAZZI; RAMOS, 2002) - potencialmente responsáveis pelas confusões terminológicas que as envolvem - justificam a sua consideração como partes integrantes de uma mesma concepção: a Educação pela Pesquisa.

Imersas na perspectiva construtivista de ensino e aprendizagem, as duas abordagens congregadas por esse termo convergem em relação a princípios e elementos norteadores das práticas de sala de aula. Destaca-se, nesse sentido, que o construtivismo como tese epistemológica defende o papel ativo do sujeito na elaboração de 
representações acerca do objeto do conhecimento. Tal tese representa, nas palavras de

Becker (1993, p. 88), a ideia de que:

[...] o conhecimento não é dado, em nenhuma instância, como algo terminado. Ele se constitui pela interação do indivíduo com o meio físico e social, com o simbolismo humano, com o mundo das relações sociais; e se constitui por força de sua ação e não por qualquer dotação prévia na bagagem hereditária ou no meio.

Tendo como importante ponto de contato entre si a valorização da pesquisa em sala de aula, tais abordagens recomendam a criação de:

[...] situações de ensino em que o aluno lide, sistematicamente, com alguns princípios inerentes ao ato de pesquisar, tais como o questionamento, a construção de argumentos, a produção escrita e o permanente diálogo entre situações do cotidiano e conteúdos escolares/acadêmicos. (ibid., p 89)

Abordando especificamente o Educar pela Pesquisa, Ramos, Lima e Rocha-Filho (2009, p. 59) conceituam-no como uma:

[...] abordagem formativa escolar, na qual os alunos e professores envolvemse ativamente, questionando a realidade e o seu próprio conhecimento, propondo ações para obter respostas às suas perguntas, de modo a reconstruir os seus argumentos, e comunicando as novas percepções e entendimentos com vistas à divulgação e à submissão à crítica na comunidade de sala de aula. Esta última etapa tem a função de contribuir para aceitação ou refutação dessas percepções e entendimentos e para a sua validação como conhecimento pessoal.

Lima (2004, p. 81) considera essencial que o professor adepto do Educar pela Pesquisa como estratégia em sala de aula crie "espaços efetivos para o aluno questionar, argumentar e escrever, entrelaçando conteúdos escolares e realidade, num processo que tem no diálogo o elemento integrador" e que tem como cerne o questionamento reconstrutivo. Esse último é tido por Demo (2007) como o responsável por conduzir à indagação recorrente da realidade e do conhecimento e por estimular reformulações que englobam teoria e prática, qualidade formal e política.

No que diz respeito à Pesquisa em Sala de Aula, Moraes, Galiazzi e Ramos (2002, p. 10) sintetizam-na como:

[...] uma das maneiras de envolver os sujeitos, alunos e professores, num processo de questionamento do discurso, das verdades implícitas e explícitas nas formações discursivas propiciando, a partir disso, a construção de argumentos que levem a novas verdades [...]. Envolver-se nesse processo é acreditar que a realidade não está pronta, mas que se constitui a partir de uma construção humana.

Os autores supracitados destacam o questionamento, a construção de argumentos e a comunicação como três princípios fundamentais inerentes à Pesquisa em Sala de Aula. Referenciam, ainda, a existência de uma relação estreita e não linear entre eles, 
avultando que, quando integrados, formam um ciclo dialético entendido por Ramos, Lima e Rocha-Filho, (2009, p. 56) como um:

\begin{abstract}
[...] movimento que se inicia com o questionamento dos alunos e do professor, problematizando o próprio conhecimento, seguido da construção de novos argumentos, mais amplos e complexos e finaliza-se com a comunicação dos resultados e o decorrente diálogo sobre esses resultados entre todos os integrantes do processo de aprendizagem. Ao longo desse processo, novos questionamentos surgem de modo que se busquem novos argumentos.
\end{abstract}

Reconhece-se, a partir do exposto, que uma breve caracterização do Educar pela Pesquisa e da Pesquisa em Sala de Aula ratifica e reforça as similaridades que essas abordagens compartilham. Destacam-se como elementos valorizados por ambas, aspectos relacionados à promoção da pesquisa como princípio pedagógico e cuja viabilização é sugerida por meio do incentivo ao questionamento, à construção de argumentos e à comunicação. Notam-se, ainda, recomendações no sentido de que tais etapas, encaradas como eixos estruturadores dessas propostas, sejam permeadas pelo diálogo e pela escrita.

Lançando luzes para a construção de argumentos em específico, foco da presente investigação, reitera-se que a argumentação se configura como elemento importante tanto do Educar pela Pesquisa quanto da Pesquisa em Sala de Aula. A partir dessa constatação, percebe-se a necessidade de avançar teoricamente nesse campo, investindo em discussões que colaborem com a construção de entendimentos acerca da promoção desse processo em aulas alicerçadas na Educação pela Pesquisa.

Apesar de a Educação pela Pesquisa ser reconhecida por preocupar-se em contribuir com o desenvolvimento da argumentação em sala de aula (RAMOS, 2000), são escassos os trabalhos que, ao proporem ou analisarem situações didáticas organizadas a partir desse enfoque, detalham o seu desenvolvimento, especificando pormenores ou pontuando aspectos de relevo inerentes às ações do professor voltadas à promoção, mediação ou avaliação desse processo nesse contexto em particular - fator que, inclusive, justifica o escopo da presente investigação. O questionamento, em contrapartida, princípio inaugural que coloca em movimento essa proposta diferenciada de ensino, costuma ser alvo de constante atenção.

No entanto, o questionamento, por si só, não é suficiente para que haja a reconstrução de conhecimentos por meio da pesquisa. A partir dele "[...] é fundamental pôr em movimento todo um conjunto de ações, de construção de argumentos que 
possibilitem superar o estado atual e atingir novos patamares do ser, do fazer e do conhecer" (MORAES; GALIAZZI; RAMOS, 2002, p. 16).

Acredita-se que investir no desvelamento de questões que envolvem a temática nebulosa e complexa da argumentação em sala de aula é uma forma de produzir subsídios que auxiliem docentes interessados no fomento dessa importante competência - caso dos professores imbuídos na Educação pela Pesquisa. Entende-se, com isso, que a construção de um denso arcabouço teórico sobre o tema, que reconheça e analise possibilidades de abordagem, trata-se de uma necessidade premente. A seção teórica apresentada é vista como um passo que pretende contribuir nesse sentido e que aproxima gradativamente as discussões ao foco da presente pesquisa.

\section{b. Argumentação na educação}

A argumentação vem ganhando destaque desde que a palavra, em detrimento da força, passou a ser utilizada como instrumento empregado na tentativa de resolução de conflitos. Pode-se dizer, portanto, que o estudo do tema acompanha a marcha civilizatória da humanidade (FIORIN, 2016).

No caminho evolutivo de valorização do processo argumentativo, muitas foram as áreas interessadas no tema, com destaque especial para a filosófica e a jurídica. Delas surgiram estudos voltados especialmente a aspectos lógicos e retóricos que se atêm à definição de componentes estruturais dos produtos gerados pela argumentação, bem como estudos voltados para a sua função persuasiva, respectivamente.

Por compor a natureza social do ser humano, que inclui a necessidade de expressão e abrange uma demanda por posicionamentos e manifestações acerca dos motivos que embasam pensamentos e ações, a atividade argumentativa permeia - ou deveria permear - as mais diversas esferas, ocupando o ambiente familiar, laboral e escolar. Ocorre que, em contrapartida ao mencionado, aproximações teóricas e práticas com o tema permitem reconhecer que o cenário educacional, que compõe o cerne desse estudo, apesar de consistir em terreno fértil para o desenvolvimento da argumentação, nunca esteve muito à vontade com o seu fomento (CHARAUDEAU, 2008).

Perelman e Olbrechts-Tyteca (2014) compartilham desse entendimento quando destacam que, apesar de a escola tratar-se de uma instituição com condições facilitadoras para o desenvolvimento da argumentação, o discurso escolar costuma ter a pretensão de aumentar a adesão ao que já é aceito, frequentemente não abrindo espaço para controvérsias e, portanto, para a argumentação. Os autores sugerem que as 
concepções dos professores, implícitas na forma com que planejam e desenvolvem suas aulas, possivelmente tenham relação com esse diagnóstico, uma vez que o discurso de autoridade de que parte dos docentes faz uso comumente limita o espaço de manifestação dos alunos e promove a repetição dos saberes transmitidos.

No ensino de Ciências, mais especificamente, o tema é considerado emergente, ainda que a aplicabilidade da argumentação não se equipare aos múltiplos benefícios a ela teoricamente atribuídos. Tais benefícios dizem respeito ao despertar de processos metacognitivos, ao desenvolvimento comunicativo e do pensamento crítico, à promoção da alfabetização científica (JIMÉNEZ-ALEIXANDRE, 2010), ao fomento à competência investigativa e epistemológica, ao favorecimento da construção de uma visão não deformada da ciência (FERRAZ; SASSERON, 2017), entre outros.

A discrepância entre as potencialidades e o pouco uso que se faz da argumentação em sala de aula é associada a problemas na formação docente e a uma consequente tendência dos professores em assumir modelos transmissivos de ensino, os quais não contemplam as possibilidades do desenvolvimento dessa importante competência em sala de aula. Como consequência, os alunos, de maneira geral, não são preparados para suprir demandas que impliquem na formulação de justificativas ou na defesa de seus próprios argumentos (JORBA, 2000).

Ademais, de acordo com Adúriz-Bravo (2017), a predominância de estudos da atualidade no Ensino de Ciências baseia-se na utilização de modelos de arquitetura do argumento, voltando-se a avaliações pontuais dos produtos da argumentação. O levantamento feito por Lima, Brandolt-Borges e Ramos (2018) corrobora tal constatação, revelando que, nos últimos 10 anos, os escassos trabalhos envolvendo a temática realizados na disciplina de Biologia ocupam-se, predominantemente, da análise da estrutura de argumentos produzidos pelos alunos por meio da aplicação do padrão argumentativo de Toulmin (2006).

A predominância do uso de abordagens atreladas à origem dos estudos argumentativos revela a necessidade de uma releitura do tema para que sua utilização no campo educacional se mostre mais adequada e, portanto, qualificada. Em meio à busca de caminhos que conduzam a novas formas de trabalhar a construção de argumentos no campo educacional, as recomendações de Wenzel (1990) descortinam possibilidades.

$\mathrm{O}$ autor propõe como alternativa para dirimir a complexidade do tema uma subdivisão do mesmo em perspectivas de ênfase. Sugere, portanto, que os interessados 
em abordar a temática argumentativa o façam orientados a partir de uma escolha entre três perspectivas possíveis, sendo elas: a perspectiva lógica, que explora o argumento como produto e aplica padrões de avaliação e validade; a perspectiva retórica, focada no processo persuasivo; e a perspectiva dialética, centrada no procedimento que regula as discussões e organiza intervenções (WENZEL, 1990).

Alguns autores explicitam essas perspectivas de forma simplificada, auxiliando na compreensão dessas dimensões. Entre eles, Mendonça e Justi (2013) identificam que: a perspectiva lógica se destina à produção de proposições que apoiam uma conclusão, determinando que um bom argumento é constituído por afirmativas embasadas por justificativas; a perspectiva retórica detém-se na produção de um discurso oral ou escrito com finalidade persuasiva; e a perspectiva dialética envolve a organização de uma interação, enfatiza debates e discussões com o intuito de produzir melhores decisões, atentando, assim, para o processo de construção de argumentos.

Esclarece-se que a perspectiva denominada por Wenzel (1990) dialética é reconhecida por Charaudeau (2008) como dialógica. O autor salienta o seu caráter emancipatório em relação aos sujeitos e problematizador no que concerne às questões de fundo. A fim de evitar confusões terminológicas com métodos de pesquisa que utilizam o termo dialética e em alusão à educação dialógica de Paulo Freire (2011) optase aqui pelo emprego do termo dialógica para designar essa vertente argumentativa.

Embora se considere que todas as perspectivas de estudo da argumentação sejam legítimas e, de certa forma, complementares, a partir das definições explicitadas pode-se adiantar a percepção inicial de que a perspectiva dialógica converge mais adequadamente com o contexto educacional. Partindo desse entendimento e procurando embasá-lo, tendo em vista tratar-se de um aspecto comumente não priorizado por pesquisas atuais, aproximações entre referenciais do tema e perspectivas de abordagem prioritariamente utilizadas serão apresentadas e discutidas a seguir.

\subsection{Referenciais da argumentação e perspectivas de ênfase associadas}

Entende-se que a argumentação em sala de aula, pelos pressupostos em que se alicerça ou mesmo pela forma como é planejada e conduzida, revela, de maneira implícita ou explícita, a intencionalidade docente que a rege, deixando assim transparecer uma tendência de alinhamento convergente com determinada perspectiva 
argumentativa. Nesse sentido, também as três perspectivas de abordagem da argumentação aqui enfatizadas revelam intencionalidades no cerne de suas definições.

De forma sintética podemos dizer que: a perspectiva lógica intenciona a construção estrutural de argumentos individuais; a perspectiva retórica pretende a persuasão ou o convencimento de terceiros; e a perspectiva dialógica objetiva um compartilhamento de ideias permeado por objeções e adensado pelo acolhimento e pela análise de justificativas plurais. Alguns referenciais típicos da argumentação são bastante reproduzidos na seara educacional e estão reconhecidamente vinculados a algumas dessas perspectivas.

É o caso de Stephen Toulmin (2006) que, ao sugerir elementos constitutivos de um argumento, vincula-se à perspectiva lógica (WENZEL, 1990), defendendo a utilização de um modelo estrutural para a geração de um produto. Segundo o modelo argumentativo de Toulmin, um argumento básico precisa conter três elementos principais: a conclusão, afirmativa cujos méritos procura-se estabelecer; os dados, evidências às quais recorremos para dar suporte às afirmativas; e a garantia, que estabelece uma conexão entre dados e conclusão (MARTINS; JUSTI, 2017).

Plantin (2018, p.245) identifica Perelman e Olbrechts-Tyteca (2014) como "neorretóricos", por representarem uma corrente que se ramificou a partir da retórica grega. Na obra Tratado da argumentação: a nova retórica, bastante utilizada na área jurídica, os autores resgatam a valorização do auditório, afirmando que todo o discurso visa à persuasão ou ao convencimento daqueles a quem se destina.

Assim, o tratado da argumentação proposto vai contra a dedução de consequências a partir de premissas, defendendo uma teoria da argumentação que, fazendo uso da razão, busca influenciar terceiros. Para tanto, seus autores recomendam: a atenção do orador ao público, de forma a garantir o interesse do auditório; o desenvolvimento da argumentação por etapas, com o intuito de facilitar o estabelecimento de relações e o seu entendimento; e a escolha de poucos argumentos, em detrimento de uma sobrecarga que possa se tornar maçante e confusa para aqueles que denominam espectadores (PERELMAN; OLBRECHTS-TYTECA, 2014).

Ressalta-se, ainda, que os próprios conceitos utilizados em diversas esferas para definir a argumentação associam-se predominantemente a vertentes lógicas ou retóricas do tema. Aranha e Martins (1999, p. 80), por exemplo, compartilham da perspectiva 
lógica ao definirem esse processo como "um tipo de operação discursiva do pensamento que consiste em encadear logicamente juízos e deles tirar uma conclusão".

A perspectiva retórica também apresenta concepções de argumentação destacadas em várias pesquisas, inclusive no cenário educacional. No livro Hablar y escribir para aprender, Jorba (2000) sugere uma definição, a respeito do que considera argumentar, que se alinha à retórica, fazendo um apanhado de definições propostas por autores que enaltecem o convencimento ou a persuasão como mote da argumentação.

Conforme exaltado, a habilidade de argumentar é fortemente associada a apelos estruturalistas ou persuasivos que suscitam questionamentos acerca de como tal destreza é concebida e desenvolvida na esfera educativa e, mais especificamente, na Educação pela Pesquisa. Visando a uma aproximação com a questão norteadora desse estudo, serão abordados pontos de contato dessa abordagem educacional com as principais vertentes argumentativas.

\subsection{Argumentação na Educação pela Pesquisa: perspectivas possíveis}

A investigação de Lima (2004) destaca-se por enfocar de forma específica os processos argumentativos desenvolvidos por meio de abordagens associadas à EPP. Buscando analisar a sala de aula do Educar pela Pesquisa, e em uma das escassas tentativas de vincular essa abordagem a alguma vertente argumentativa, a autora considerou - na ocasião de sua tese - a proposta de Boaventura de Souza Santos (2017), denominada novíssima retórica ou retórica da pós-modernidade, como pertinente para o desenvolvimento da argumentação em aulas com pesquisa.

Tal consideração fundamentou-se nos avanços trazidos por essa proposta, entre eles a visão de que a argumentação só tem sentido quando contribui para o conhecimento-emancipação, ou seja, para o conhecimento que se pretende crítico, e a ênfase dada ao diálogo, convertendo-o no princípio regulador da prática argumentativa, que reconhece a necessidade de uma interação maior entre auditório e orador no que o autor denomina de "retórica dialógica".

Apesar dos avanços significativos, que enaltecem a criticidade e o dialogismo como características imprescindíveis a serem fomentadas quando se trabalha com argumentação em sala de aula, percebe-se, na proposta de Santos (2017), a permanência da ênfase no convencimento e, portanto, o vínculo estreito com a perspectiva retórica. Entende-se que a preservação da intencionalidade persuasiva, por atrelar-se a formas de 
impor, vencer, subjugar, assujeitar ou dominar o outro, destoa de objetivos educacionais emancipatórios almejados pela concepção da Educação pela Pesquisa.

A EPP insere-se em um referencial que defende o investimento em uma educação libertadora, que reconhece o valor das diferenças, da cooperação e da autonomia. Adensando essa constatação, percebe-se, ainda, um descompasso intrínseco no termo retórica-dialógica, tendo em vista que o dialogismo nega a predileção por deliberações individuais, autoritárias e verticalizadas, e a retórica tem conotação coercitiva. Acreditase que a incoerência revelada depõe contra a utilização dessa terminologia para definir a argumentação proposta na seara da Educação pela Pesquisa.

Outros expoentes da Educação pela Pesquisa, cientes da conotação retórica frequentemente associada à argumentação, buscam elementos que justifiquem o seu uso. É o caso de Ramos (2002, p. 30) quando, em uma tentativa de atenuar o uso do convencimento como finalidade da atividade argumentativa, indica que, apesar de existirem outras finalidades para tal, por vezes "é necessário vencer ou tentar convencer os outros para que fiquemos convencidos das nossas próprias ideias, para que minimizemos nossas dúvidas”. Ressalta-se e concorda-se, nesse ponto, com o essencial papel do outro para a constituição própria de cada ser.

Destaca-se, em adendo, que a vinculação da argumentação ao dialogismo amplifica a relevância da alteridade, na medida em que oferece ao outro a possibilidade de não apenas reforçar entendimentos, mas de duvidar deles e, até mesmo, desconstruílos, permitindo que o conhecimento avance por meio do pensar sobre o pensar. A prática da reflexão acerca das nossas impressões e de como elas se fundamentam relaciona-se com o despertar de processos metacognitivos, os quais já foram citados nesse aporte teórico entre os benefícios relativos ao desenvolvimento da argumentação.

Plantin (2018, p. 265) reforça as críticas ao caráter retórico da argumentação quando analisa:

Aquele que persuade, aristocrata da palavra, é colocado na alta posição de quem visa o universal, enquanto os membros do auditório ocupam a posição baixa e sem substância dos que não sabem, são incapazes de raciocinar, de decidir, devendo ser guiados e ficando vulneráveis diante da enganação e da manipulação do outro.

A transposição desses papéis para a esfera educativa fundamenta a consideração da perspectiva retórica como inapropriada para esse âmbito. Por isso, Plantin (2018, p. 
266) advoga a favor da possibilidade de uma "co-construção de conclusões, em detrimento de uma colonização de mentes". Nesse sentido, indica que a primeira alternativa representa o estado normal das coisas e da democracia, em que as diferenças de opinião fazem parte dos grupos humanos e exigem uma gestão das diferenças; e a segunda considera a diferença ruim e a unanimidade como desejável, sugerindo que se ingresse em uma era em que importa mais conviver do que convencer.

Compartilhando desses entendimentos, defende-se que a intencionalidade dialógica da argumentação na educação, mais especificamente na Educação pela Pesquisa, constitui-se em uma escolha mais pertinente e representa de forma mais adequada a argumentação desenvolvida em meio a essa abordagem formativa escolar. Destaca-se, em função disso, a necessidade de assumir explicitamente essa vinculação, fundamentando-a e, como consequência disso, fortalecendo-a.

Dito em outras palavras, não basta que se sugira ou se reconheça a intersecção "Educação pela Pesquisa e argumentação dialógica". Fazem-se necessárias a busca e a reunião de elementos que a demonstrem e a justifiquem. Nesse sentido, mais do que apresentar a perspectiva dialógica como possibilidade voltada ao alcance de objetivos educacionais emancipatórios, é preciso construir argumentos em favor dessa intersecção, evidenciando convergências, entre a vertente dialógica da argumentação e a EPP, que justifiquem a relação e a adequação entre essa perspectiva argumentativa e essa proposta de ensino e aprendizagem. A seção a seguir se voltará a essas questões.

\section{RESULTADOS: Argumentação dialógica e EPP}

A partir da exposição de particularidades das perspectivas lógica e retórica da argumentação - que desabonam o uso dessas vertentes no contexto educacional -, a perspectiva dialógica do tema surge como uma vertente alternativa e com potencial qualificador do desenvolvimento dessa competência em sala de aula. Fazem-se necessárias, nesse sentido, a reunião e a pormenorização de aspectos relativos a essa forma dialógica de construir argumentos, a qual nem sempre é apresentada de forma explícita e, em alguns casos, precisa ser percebida.

Leitão (1999) é um dos autores que há anos deixa transparecer a recomendação de um olhar dialógico para a argumentação, pois exalta a necessidade de que o tema adquira uma dimensão epistêmica e o institui como recurso privilegiado de mediação 
em processos de construção de conhecimento, sugerindo que a negociação e a mudança sejam assumidas como características definidoras da argumentação.

O engajamento do indivíduo é visto, portanto, como um pré-requisito fundamental para mudanças, ainda que, por si só, não as garanta. Isso porque, apesar da defesa de um ponto de vista demarcar uma etapa argumentativa (ALVES CONSTANTINO et al., 2019), é preciso avançar no sentido dialógico. Esse avanço requer o estabelecimento de um contraste entre a posição defendida em um argumento e dúvidas ou pontos de vista alternativos que impulsionem um exame de posições à luz de perspectivas contrárias (DE CHIARO; LEITÃO, 2005). Tais discussões vão ao encontro do já avultado papel do outro para a construção de posicionamentos individuais.

Aprofundando o debate, De Chiaro e Leitão (2005) defendem que os tópicos sobre os quais se argumenta precisam ser questões abertas, incertas e sujeitas à discussão, em oposição ao que ocorre com grande parte dos conteúdos curriculares. Defendem ainda que a negociação de pontos de vista divergentes pressupõe a possibilidade de mudança de visão por qualquer parte dos participantes envolvidos na discussão, incluindo a figura docente, que precisa colocar-se na posição de interlocutor. Finalmente, advogam sobre a necessidade de o resultado do processo de argumentação configurar-se em um ponto de chegada, a princípio, desconhecido.

Percebe-se, pelo exposto, que as características associadas à perspectiva dialógica se aproximam dos pressupostos da Educação pela Pesquisa. Entre os entrelaçamentos constatados destaca-se o compartilhamento da necessidade de atribuir uma visão epistêmica à argumentação. Tal aspecto teórico é almejado no exercício da Educação pela Pesquisa, tendo em vista ser a construção de argumentos elencada como uma etapa imprescindível ao processo de reconstrução de conhecimentos.

Também Bernardo (2007) defende a Educação pelo Argumento como uma opção metodológica, afirmando que cabe à escola eleger a argumentação como eixo de todas as suas ações pedagógicas. Nesse sentido, ainda que não possa responder por decisões institucionais, entende-se que compete ao professor realizar suas próprias escolhas e organizar sua prática a partir de concepções que valorizem a argumentação. Esse é o caso dos docentes que ancoram suas ações a partir da EPP, alicerçando o processo de ensino e aprendizagem por meio da construção de argumentos. 
O protagonismo estudantil, exaltado teoricamente como aspecto necessário à promoção da argumentação dialógica em sala de aula, é também reconhecido como elemento fundamental por abordagens que encaram a pesquisa como princípio pedagógico. Demo (2007), em passagem que versa a esse respeito, aponta como preocupações centrais da Educação pela Pesquisa a necessidade de deslocar o aluno da sua condição passiva e subalterna, cujas principais atividades são a repetição e a cópia, para a condição de sujeito atuante nas aprendizagens realizadas, por meio do uso de estratégias de ensino que exijam dele a busca de informações, a elaboração própria e a permanente reconstrução do conhecimento.

A convergência evidenciada abarca, em seu cerne, outras aproximações e derivações, pois a percepção do aluno como protagonista, por exemplo, abriga a necessidade de atenção às demandas e aos interesses estudantis. Nesse contexto, surge a importância de lançar luzes às perguntas elaboradas pelos alunos e, ademais, de problematizar os temas emergentes, provocando e incentivando manifestações.

Indo ao encontro do percebido, Ortega, Alzate e Bargalló (2015), referindo-se à maneira como os professores promovem a argumentação em aulas de ciências, destacam a necessidade de investir em processos dialógicos que transformem a ação monológica e autoritária do docente em uma ação mediadora e promotora de espaços de discussão em grupo. As autoras utilizam o termo indagação dialógica - de Gordon Wells (2007) para definir "questionamentos que problematizem o conhecimento, permitindo a exposição de pontos de vista, debates, críticas e, possivelmente, a construção de conclusões mais significativas e mais compreensíveis sobre os fenômenos ou temas estudados" (ORTEGA; ALZATE; BARGALLÓ, 2015, p. 633, tradução nossa).

A argumentação dialógica é nomenclatura explicitamente utilizada por Boulter e Gilbert (1995) para classificar processos baseados no compartilhamento de ideias dos alunos entre si e com o professor a partir de interações que promovem conflitos internos e demandam a explicitação de conclusões. Os autores referem que esse tipo de argumentação distancia o professor da figura de detentor do conhecimento e gera uma troca de ideias menos centralizada, exigindo a definição do papel do professor como mediador de concepções dos alunos e de conceitos cientificamente aceitos.

A adesão aos pressupostos debatidos - que entrelaçam a EPP e a argumentação dialógica- exige do docente imbuído dessa abordagem formativa escolar e, portanto, 
voltado a essa vertente argumentativa, o desenvolvimento de determinadas destrezas, entre elas a capacidade de lidar com a instabilidade e a flexibilidade que a pesquisa e a argumentação demandam e a habilidade de mediar processos e propor intervenções. Isso porque o não fornecimento de receitas prontas a serem aplicadas genericamente a todas às aulas e atividades é um fator que possibilita que cada professor utilize certos instrumentos e encaminhe de determinada forma as atividades com os seus alunos (LIMA, 2004), atentando para a necessidade de consonância com os princípios que determinam a essência dessas propostas.

A flexibilidade situacional é característica que, ao mesmo tempo, requer e permite a atenção a determinados aspectos. Um deles é o de que a pergunta em sala de aula seja ela proveniente dos alunos ou oriunda do professor - ganhe o status de questão aberta, exigindo que o grupo se mobilize em busca de respostas possíveis e dando às propostas de sala de aula um caráter investigativo. A natureza incerta das perguntas, portanto, é que possibilita a emergência de ideias e as consequentes discussões entre diferentes respostas elaboradas e pontos de vistas expressos, permitindo o requisitado envolvimento necessário ao movimento de construção de argumentos.

O caráter discutível e mutável desse tipo de argumentação indica que o desenvolvimento dessa competência - nos padrões da perspectiva dialógica - associa-se a um processo social e colaborativo. Marques (1993, p. 99), traduzindo as ideias de Habermas, denomina a argumentação como um processo que conduz os "[...] interlocutores ao entendimento de algo novo, cooperativamente produzido, uma vez que não resulta da vitória de um sobre os demais e não é a simples soma dos diversos pontos de vista, mas a reconstrução coletiva de um consenso".

Evidencia-se, nesse ponto das discussões propostas, que as definições de argumentação manifestas convergem com a perspectiva dialógica e, ainda mais, aproximam-se da intencionalidade e da operacionalização dos princípios preconizados pela EPP. Dito em outras palavras, nota-se que os conceitos explícitos conduzem à percepção de que a argumentação dialógica abriga objetivos relacionados à reconstrução de conhecimentos e à(s) forma(s) de atuação docente sugerida(s) para o seu alcance na concepção da EPP.

Moraes, Galiazzi e Ramos (2002) ratificam esse entendimento quando, ao discorrerem sobre a Pesquisa em Sala de Aula, declaram explicitamente que as 
compreensões advindas das atividades desenvolvidas sob essa égide adquirem caráter provisório e que a validação ou não dos entendimentos pelo grupo propicia momentos de diálogo crítico. Para Novakowski Kierepka e Zanon (2019) esse tipo de diálogo fomenta a construção da capacidade de reflexão.

Fica evidente, pelo exposto, que a comunicação é condição fundamental para que o diálogo se estabeleça e, portanto, para que a argumentação dialógica seja desencadeada. É a comunicação que possibilita a expressão dos entendimentos iniciais, a exposição de refutações e concordâncias, a mediação das concepções intermediárias, a manifestação dos argumentos reconstruídos e, inclusive, a elaboração de novas perguntas que impulsionam o ingresso em um outro ciclo de construção de argumentos baseados no diálogo e na pesquisa.

\section{CONSIDERAÇÕES FINAIS}

O presente estudo emergiu da constatação da necessidade de se investir no aprofundamento de questões referentes ao desenvolvimento da competência argumentativa na escola. Ademais, derivou-se de uma demanda de busca por alternativas à reprodução de padrões reconhecidamente utilizados por outras áreas do conhecimento e considerados inadequados ao âmbito educacional.

Partindo de uma proposta de subdivisão do tema em perspectivas de ênfase - e das suas definições - e por meio do conhecimento dos pressupostos que embasam a Educação pela Pesquisa e que reconhecem a importância dos processos argumentativos em sala de aula, pôde-se perceber distanciamentos e aproximações entre a abordagem da EPP e três principais vertentes argumentativas recomendadas ao estudo do tema.

Notou-se, assim, uma dissociação natural da EPP de proposições coercitivas ou estruturalistas da argumentação, aspecto que afastou a promoção dessa competência, nessa seara, das vertentes lógica e retórica. Ao mesmo tempo, descortinou-se a associação da EPP à intencionalidade dialógica da argumentação, fortemente relacionada à organização de intervenções e cuja ênfase situa-se na condução de discussões que oportunizam a reconstrução de argumentos e de conhecimento.

Foram pressupostos compartilhados e que, portanto, fundamentaram a vinculação entre a EPP e a argumentação dialógica: a valorização do protagonismo estudantil; a necessidade de interlocução entre os agentes educacionais; o 
reconhecimento da pluralidade de ideias emergentes; a visão da (re)construção do conhecimento como um processo dinâmico e flexível; a noção do dialogismo como elemento favorecedor desses elementos. A argumentação dialógica é vista, portanto, como uma forma de os alunos buscarem ativamente o conhecimento, elaborando e reconstruindo argumentos por meio do diálogo e sob a mediação do professor que educa pela pesquisa.

Analisa-se, a partir desse estudo, que: a vertente dialógica da argumentação traz consigo uma possibilidade de releitura para a promoção mais adequada dessa competência na escola; a vinculação com a perspectiva dialógica possibilita a exploração dos múltiplos benefícios atribuídos ao desenvolvimento da argumentação em sala de aula, auxiliando na promoção da autonomia e do pensamento crítico; abordagens que consideram a pesquisa como princípio pedagógico favorecem o desenvolvimento da argumentação por meio dessa perspectiva.

Destaca-se, oportunamente, a importância da construção de conhecimentos referentes às possibilidades de desenvolvimento da argumentação na escola, na medida em que a falta de clareza nesse sentido é capaz de conduzir a um negligenciamento do processo, levar ao desprezo do seu potencial ou mesmo a incoerências teórico-práticas a partir de um desacordo entre intenções e ações docentes.

Nesse sentido, as contribuições teóricas advindas desse estudo apontam para a necessidade de ampliação e aprofundamento investigativo do tema. Conduzem, portanto, à recomendação de estudos complementares em que se busque analisar, lançando luzes para a ação docente, de que forma os pressupostos dialógicos da argumentação na EPP são desenvolvidos na prática da sala de aula.

\section{REFERÊNCIAS BIBLIOGRÁFICAS}

ADÚRIZ-BRAVO, Agustín. Puentes entre la argumentación y la modelizacion em la enseñanza de las Ciencias. In: X Congresso Internacional sobre investigación em didáctica de las Ciencias. 2017. Sevilla. p. 4491-4495. Anais. Sevilla. Sep. 2017. Disponível em: https://ddd.uab.cat/pub/edlc/edlc_a2017nEXTRA/27._puentes_entre _la_argumentacion_y_la_modelizacion_en_la_ensenanza.pdf Acesso em: 07 mai. 2020.

ALVES CONSTANTINO, A.; MACHADO DORNELES, A.; SOARES MOTTA, C.; SILVA DOS SANTOS, A. Pesquisa na Sala de Aula de Química: narrativas das aprendizagens da docência partilhada. Revista Insignare Scientia - RIS, v. 2, n. 2, p. 240-254, 19 set. 2019.

ARANHA, Maria Lúcia de Arruda; MARTINS, Maria Helena Pires. Filosofando: introdução à filosofia. São Paulo: Moderna,1999.

Recebido em: $01 / 09 / 2020$

Aceito em: $27 / 10 / 2020$ 
BECKER, Fernando. O que é construtivismo. São Paulo: FDE, n.20, p.87-93, 1993.

BERNARDO, Gustavo. Educação pelo Argumento. 1a ed. Rio de Janeiro: Rocco, 2007.

BOUlTER, Carolyn; GILBERT, John. Argument and Science Education. In: COSTELL, P. J. M.; MITCHEL, S. Competing and consensual voices: theory and practice of argumentation. Cleveland: Inglaterra. Multilingual Matters, 1995.

CHARAUDEAU, Patrick. Linguagem e Discurso: modos de organização. São Paulo: Contexto, 2008.

DE CHIARO, Sylvia; LEITÃO, Selma. O papel do professor na construção discursiva da argumentação em sala de aula. Psicologia: reflexão e crítica, 18 (3), pp. 350-377, 2005. Disponível em: http://www.scielo.br/pdf/prc/v18n3/a09v18n3.pdf Acesso em: 3 dez. 2018.

DEMO, Pedro. Educar pela Pesquisa. 8. ${ }^{a}$ ed. Campinas, SP: Autores Associados, 2007.

DEMO, Pedro. Pesquisa e construção do conhecimento. $2^{\text {a }}$ ed. Rio de Janeiro: Tempo Brasileiro, 1994.

FERRAZ, Arthur Tadeu; SASSERON, Lúcia Helena. Propósitos epistêmicos para a promoção da argumentação em aulas investigativas. Investigações em Ensino de Ciências. V.22, n.1, pp 42-60, abr. 2017. Disponível em: https://www.if.ufrgs.br/ cref/ojs/index.php /ienci/article/view/312 Acesso em: 20 jun. 2020.

FIORIN, José Luiz. Argumentação. 1. ${ }^{a}$ ed., 2. ${ }^{a}$ reimpressão. São Paulo: Contexto, 2016.

FREIRE, Paulo. Pedagogia do Oprimido. 50. edição. Rio de Janeiro: Paz e Terra, 2011.

JIMÉNEZ-ALEIXANDRE, María Pilar. 10 Ideas clave: Competencias en argumentación y uso de pruebas. Barcelona: Graó, 2010.

JORBA, Jaume; GÓMEZ, Isabel y PRAT, Angeles. Hablar y escribir para aprender: uso de la lengua em situación de enseñanza-aprendizaje desde las áreas curriculares. Madrid: Editora Sínteses, 2000.

LEITÃO, Selma. Contribuições dos estudos contemporâneos da argumentação a uma análise psicológica de processos de construção de conhecimento em sala de aula. Arquivos brasileiros de psicologia, v.1, pp 91-109, 1999. Disponível em: http://pesquisa.bvsalud.org/portal/resource/pt/lil-278539?lang=es Acesso em: 24 out. 2019. 
LIMA, V. M do R. A sala de aula do Educar pela Pesquisa: uma história a ser contada. 2004. Tese. Doutorado em Educação em Ciências e Matemática. Pontifícia Universidade Católica do Rio Grande do Sul, Porto Alegre, 2004.

LIMA, Valderez Marina do; BRANDOLT-BORGES, Thelma Duarte; RAMOS, Maurivan Güntzel. Argumentação no ensino de Ciências: estado do conhecimento das produções stricto sensu brasileiras nos últimos dez anos. Dynamis, v. 24, p. 58-75, 2018. Disponível em: file:///C:/Users/thelm/AppData/Local/Packages/Microsoft. MicrosoftEdge_8wekyb3d8bbwe/TempState/Downloads/7146-23942-1-PB\%20(1).pdf Acesso em: 3 jan. 2020.

MARQUES, Mário Osório. Conhecimento e modernidade em construção. Ijuí: UNIJUÍ, 1993.

MARTINS, Marina; JUSTI, Rosária da Silva. Uma nova metodologia para analisar raciocínios argumentativos. Ciência \& Educação (Bauru). v. 23, n. 1, jan./mar., 2017. Disponível em: http://www.scielo.br/scielo.php?script=sci_arttext\&pid=S151673132017000100007 Acesso em: 11 mai. 2017.

MENDONÇA, Paula Cristina Cardoso; JUSTI, Rosária da Silva. Ensino-Aprendizagem de Ciências e Argumentação: discussões e questões atuais. Revista Brasileira de Pesquisa em Educação em Ciências. v. 13, n. 2, p. 187-216, 2013. Disponível em: https://seer.ufmg.br/index.php/rbpec/article/view/2461. Acesso em: 24 abr. 2018.

MORAES, Roque; GALIAZZI, Maria Carmo; RAMOS, Maurivan Güntzel. Pesquisa em sala de aula: fundamentos e pressupostos. In: MORAES, R.; LIMA, V. M. R. Pesquisa em sala de aula: tendências para a educação em novos tempos. 1. ed. Porto Alegre: Edipucrs, 2002. p. 9-23.

NOVAKOWSKI KIEREPKA, J.; ZANON, L. B. Problematização e reconhecimento de teorias e práticas de professores em formação para o ensino de Ciências com foco no educar pela pesquisa. Revista Insignare Scientia - RIS, v. 2, n. 1, p. 1-20, 20 maio 2019.

ORTEGA, Francisco Javier Ruiz; ALZATE, Oscar Eugênio Tamayo; BARGALLÓ, Conxita Marquez. La argumentación em classe de ciências: um modelo para su enseñanza. Educação e Pesquisa, v. 41, n. 3, p. 629-646, 2015. Disponível em: http://www.scielo.br/pdf/ep/v41n3/1517-9702-ep-41-3-0629.pdf Acesso em: 4 jun. 2020.

PAUleTti, Fabiana. A Pesquisa como princípio educativo no ensino de Ciências: concepções e práticas em contextos brasileiros. 2018. Tese (Doutorado em Educação em Ciências e Matemática). Programa de Pós-Graduação em Educação em Ciências e Matemática. PUCRS, Porto Alegre, 2018.

PERELMAN, Chaim; OLBRECHTS-TYTECA, Lucie. Tratado da Argumentação A Nova Retórica. $3^{\text {a }}$ ed. São Paulo: Editora Martins Fontes. 2014.

PLANTIN, Christian. Não se trata de convencer, mas de conviver: a era pós-persuasão. Revista Eletrônica de Estudos Integrados em Discurso e Argumentação. Ilhéus, n. 
15, jan/jun.2018. Disponível em: http://periodicos.uesc.br/index.php /eidea/ article/ view/2066 Acesso em: 17 mar. 2019.

RAMOS, Maurivan Güntzel. Educar pela Pesquisa é Educar para a Argumentação. IN: MORAES, Roque e LIMA, Valderez Marina do Rosário. (Orgs.). Pesquisa em Sala de Aula: tendências para a Educação em Novos Tempos. Porto Alegre: EDIPUCRS, 2002, p. $25-49$.

RAMOS, Maurivan Güntzel. Os desafios da educação pela pesquisa: dos limites da realidade às possibilidades de educar para a argumentação. In: IV ANPEd-SUL Seminário de Pesquisa em Educação da Região Sul, Anais. Porto Alegre, 2000. CD.

RAMOS, Maurivan Güntzel; LIMA, Valderez Marina do Rosário Lima; ROCHAFILHO, João Bernardes. A Pesquisa como Prática na Sala de Aula de Ciências e Matemática: um olhar sobre dissertações. Alexandria Revista de Educação em Ciências e Tecnologia, v.2, n.3, p.53-81, nov.2009.

SANTOS, Boaventura de Souza. A crítica da razão indolente: contra o desperdício da experiência. $8^{\text {a }}$ ed. São Paulo: Cortez, 2017.

TOULMIN, Stephen. Os usos do argumento. Tradução Reinaldo Guarany. 2. ed. São Paulo: Martins Fontes, 2006.

WELLS, Gordon. Indagación dialógica: hacia uma teoria e uma práctica socioculturales de la educación. Barcelona, Paidos Iberica, 2001.

WENZEL, J. Perspectives on Argument: rhetoric, dialectic, logic. In: TRAPP, Robert; SCHUETZ, Janice (eds.) Perspectives on Argumentation: essays in honor of Wayne Brockriede. Prospect Heights, Illinois: Waveland Press, p.9-26, 1990. 